\title{
Assessing the Use of Glycine Powder Air Polishing in Periodontal Maintenance Therapy
}

\author{
Mariam Katit ${ }^{1}$, Ali Abosulaiman ${ }^{2}$, Salah Shehade ${ }^{3}$, Mohammad M Alsabbagh $^{4}$
}

\begin{abstract}
Aim: The aim of this study is to evaluate the clinical efficacy of subgingival glycine powder air polishing in periodontitis during PMT. Materials and methods: Forty PMT patients were recruited from subjects referred to the Department of Periodontology, Faculty of Dentistry, Damascus University. AgP group comprised twenty patients diagnosed with generalized aggressive periodontitis, whereas ChP group included 20 patients diagnosed with generalized chronic periodontitis. Using a split mouth study design, subgingival plaque was removed by means of glycine powder air polishing GPAP or curettes MCD. Clinical periodontal parameters were recorded at baseline and at 3 months after treatment. A visual analog scale was used to evaluate inconvenience during therapy.

Results: The two studied groups showed improvements in all clinical indices after 3 months $(p=0.001)$. There were no significant statistical differences between GPAP and MCD in both of AgP and ChP groups $(p>0.05)$. GPAP therapy was significantly less painful than MCD in AgP and ChP groups ( $p=0.018, p=0.038$, respectively).

Conclusion: Subgingival glycine air polishing was effective in treatment periodontitis during maintenance care and perceived to be more acceptable by the patients than conventional curettes.

Clinical significance: Subgingival glycine air polishing has been shown to remove biofilm in periodontal pockets without causing damage to the root surfaces or soft tissues; therefore, it was suggested to be used as an alternative to repeated use of conventional curettes in periodontal maintenance therapy (PMT).
\end{abstract}

Keywords: Dental polishing, Glycine, Periodontitis.

World Journal of Dentistry (2019): 10.5005/jp-journals-10015-1650

\section{INTRODUCTION}

Dental plaque biofilm plays a major role in the etiology of gingivitis and periodontitis. ${ }^{1}$ The regular mechanical removal of bacterial plaque from all dental surfaces is, therefore, the primary means of preventing and stopping the progression of periodontal disease. In patients with periodontitis, it is necessary to perform recurrent subgingival debridement in pockets deeper than $3 \mathrm{~mm}$ to maintain periodontal health. ${ }^{2}$

It has been shown that the maintenance phase following the effective initial therapy prevents the recurrence of gingivitis and reduces the risk of developing periodontitis. The therapeutic effectiveness of maintenance phase may be mainly due to the removal of plaque and calculus from supra and subgingival areas that cannot be reached by the patient's oral care. ${ }^{3}$

Conventional curettes or ultrasonic scalers are usually used to control subgingival biofilm; however, they need a long time, and their application frequently leads to the loss of root material over time. ${ }^{4}$ Hence, several recent studies suggested to use air polishing devices that generate powder and water with compressed air to remove the microbial biofilm. ${ }^{5-8}$

The subgingival air polishing technique using traditional abrasive powders such as sodium bicarbonate is contraindicated due to the large damage caused to the root surface during the application of the device for a short time. This injury becomes clinically clear because of the cumulative effect of the abrasive powder with the repeated application during maintenance therapy. ${ }^{9}$ To overcome this problem, a low-abrasive powder has been developed that allows sufficient removal of the plaque from the root surface without damaging the root cementum.

Glycine powder consists of crystals of spherically compatible organic salts that slowly dissolves in water and therefore can be

\footnotetext{
1,2,4 Department of Periodontology, Faculty of Dentistry, Damascus University, Syria

${ }^{3}$ Department of Microbiology, Faculty of Medicine, Damascus University, Syria

Corresponding Author: Mariam Katit, Department of Periodontology, Faculty ofDentistry, Damascus University, Syria, Phone:+936988638528, e-mail:mariamkutit@gmail.com
}

How to cite this article: Katit M, Abosulaiman A, Shehade $S$, et al. Assessing the Use of Glycine Powder Air Polishing in Periodontal Maintenance Therapy. World J Dent 2019;10(4):259-263.

Source of support: Damascus University

Conflict of interest: None

used to remove subgingival plaque during maintenance therapy. Glycine is one of the most important low-abrasive powders used in subgingival air polishing. ${ }^{10}$ A study by Petersilka et al. reported that glycine powder was safe and cause less damage to gingival tissues compared with sodium bicarbonate powder and manual curettes. ${ }^{11}$

Recently, nozzles have been developed to deliver low-abrasive powder to the subgingival area to remove biofilm. The most notable differences involve the type of powder used and the nozzle designed to be inserted into the periodontal pocket with a depth of $4 \mathrm{~mm}$ or more. Clinical studies have demonstrated the effectiveness of this technique in removing the plaque without damaging soft tissues, enamel, dentin, or cementum. ${ }^{10,11}$

\section{Aım}

The aim of the present study was to evaluate the clinical efficacy of subgingival glycine powder air polishing in aggressive and chronic periodontitis during periodontal maintenance therapy. 


\section{Materials and Methods}

\section{Study Design}

The present study was designed as a controlled randomized, parallel-group clinical trial. All patients gave their written consent for participation in the study after being informed individually about the nature of the planned treatment.

\section{Study Population}

Forty subjects were recruited from patients referred to the Department of Periodontology at the Faculty of Dentistry, University of Damascus. The study was conducted between February 2017 and December 2018. Patients were allocated into two groups: AgP group comprised 20 patients (6 males, 14 females, age: $20-30$ years) diagnosed with generalized aggressive periodontitis, whereas $\mathrm{ChP}$ group included 20 patients ( 11 males, 9 females, age: $36-65$ years) diagnosed with generalized chronic periodontitis. Each patient had to meet the following inclusion criteria: Patients were systemically healthy but clinically and radiographically diagnosed with GAgP and GChP according to the classification of the American Academy of Periodontology in 1999. Patients received surgical or nonsurgical periodontal treatment from 6 months and 3 months, respectively. The presence of $\geq 12$ teeth in lower arch 6 teeth in each quadrant. Each quadrant had a minimum of two sites with probing depth $\geq 4$ $\mathrm{mm}$. On the contrary, exclusion was made as follows: pregnancy, chronic bronchitis, asthma, current smokers or alcoholics, the use of antibiotics, and anti-inflammatory drugs in the previous 3 months before the study.

\section{Clinical Study}

At the first visit, a well-qualified periodontal specialist (MK) removed any hard or soft supragingival deposits (plaque, stain, calculus). Patients' daily oral hygiene was reestablished, and all participants were taught to use the same brushing technique (Bass method). Later, all patients were asked to brush their teeth three times a day after assessing their capability of executing the correct oral hygiene instructions.

At the second visit, the following clinical periodontal parameters were recorded: probing depth (PD), clinical attachment level $(\mathrm{CAL}){ }^{12}$ plaque index (PI), ${ }^{13}$ bleeding on probing (BOP) ${ }^{14}$ and gingival inflammation (GI). ${ }^{15}$ Measurements were taken at six surfaces per tooth (mesiofacial, buccal, distofacial, mesiolingual, lingual, distolingual) using a standard periodontal probe (PCPUNC15, Hu-Friedy).

Subsequently, subjects were randomly allotted to receive the GPAP treatment in one quadrant and the MCD treatment in another quadrant by means of a lot draw.

A split mouth design was utilized in removing subgingival plaque in PMT patients either using subgingival glycine powder air polishing (GPAP) (Fig. 1) or manual curettes debridement (MCD) (Fig. 2).

In the GPAP group, an air polishing device with a handpiece (Air-Flow ${ }^{\circledast}$ Handy Perio, EMS, Nyon, Switzerland) was equipped with a fine-grain glycine powder (Air-Flow Subgingival Perio, EMS). A special thin, wedge-shaped nozzle (PERIO-FLOW ${ }^{\circledR}$ nozzle, EMS) was designed to be mounted on the handpiece in order to allow access to the subgingival area with three holes perpendicularly oriented to the long axis, allowing the air-powder mixture to flow horizontally (Fig. 3).

The air polishing device was set according to the manufacturer's instructions. The powder chamber of the air polishing device used in this study was filled before use for each patient. The nozzle is gently inserted into the pocket parallel to the longitudinal dental axis until resistant is felt and then lifted slightly away from the bottom of the pocket (Fig. 4). The device was activated and the nozzle was moved subgingivally on the entire root surface with a circular motion for 5 seconds for each surface of the root.

Later on, in the MCD group conventional periodontal debridement was applied. The work continued until the surface of the root was free of all clinically detectable accumulation when examined with a periodontal probe. The periodontal debridement was achieved by Gracey curettes (Gracey curette ${ }^{\circledR}$, Ziffaro ${ }^{\mathrm{TM}}$, Germany) without local anesthesia. There was no time limit for the hand instrumentation.

At the end of the visit, patients were asked to rate the pain felt after each treatment using a visual analog scale VAS $^{16}$ by giving a number from 1 to 10 . In addition, they were asked to give their feedback regarding the treatment. The subjects were recalled after three months. The same examiner recorded clinical periodontal parameters.

\section{Statistical Analysis}

A statistical software program SPSS (version 21, Chicago, IL, USA) was used to process the collected data and perform statistical testing. The Wilcoxon test was used to analyze the differences over time in the same group before and after treatment. The Mann-Whitney $U$ test was used to assess differences between study groups. Values of $p<0.05$ were considered as statistically significant at a significance level of $95 \%$.

\section{Results}

The main characteristics of the study population are presented in Table 1 . In this study, a total of 40 subjects were recruited. There were 9 (45\%) females and 11 (55\%) males in ChP group, while AgP group had 14 (70\%) females and 6 (30\%) males (Table 1).

\section{ChP Group Results}

Table 2 shows the mean of the periodontal clinical parameters in GPAP and MCD ChP groups at baseline and three months posttherapy. The two groups demonstrated statistically significant improvements $(p<0.05)$.

There were no statistically significant differences in the mean values of periodontal parameters between GPAP and MCD in ChP group at baseline and three months post-therapy $(p>0.05)$



Fig. 1: Plaque removal by subgingival glycine powder air polishing 


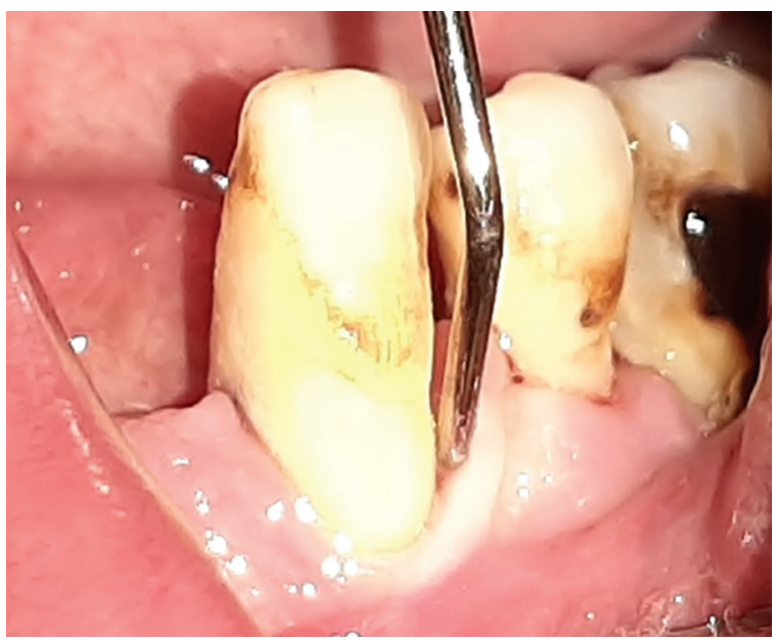

Fig. 2: Manual curettes debridement

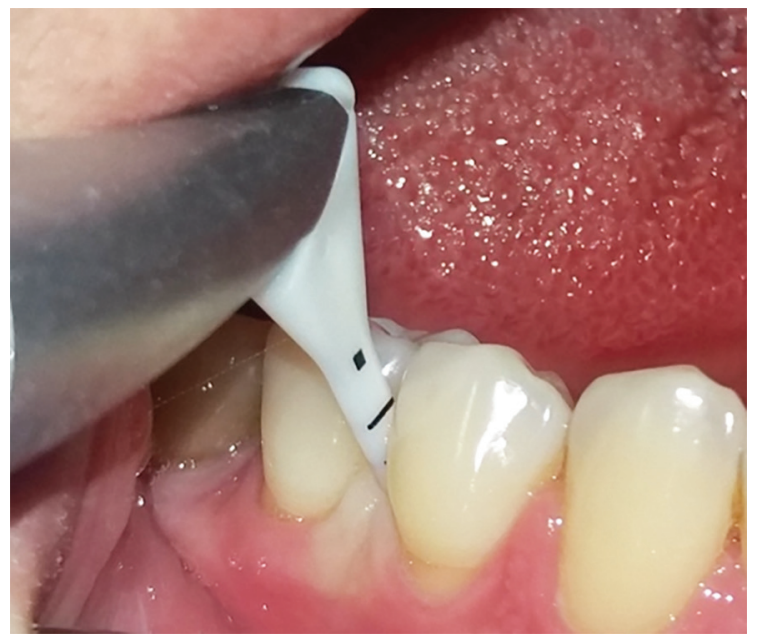

Fig. 4: Clinical application of the device in a periodontal pocket

Table 1: Demographic parameters of the study population

\begin{tabular}{|c|c|c|c|c|}
\hline \multicolumn{2}{|l|}{ Patient data } & $A g P$ & ChP & Total \\
\hline \multicolumn{2}{|l|}{$N$} & 20 & 20 & 40 \\
\hline \multicolumn{2}{|c|}{ Age (years) mean (range) } & $\begin{array}{l}23.75 \\
(20-30)\end{array}$ & $\begin{array}{l}51.75 \\
(36-65)\end{array}$ & $\begin{array}{l}37.75 \\
(20-65)\end{array}$ \\
\hline \multirow[t]{2}{*}{$\operatorname{Sex}(n,[\%])$} & Female & $14(70 \%)$ & $9(45 \%)$ & $23(57.5 \%)$ \\
\hline & Male & 6 (30\%) & $11(45 \%)$ & $17(42.5 \%)$ \\
\hline
\end{tabular}

$\mathrm{AgP}$, aggressive periodontitis group; $\mathrm{ChP}$, chronic periodontitis group

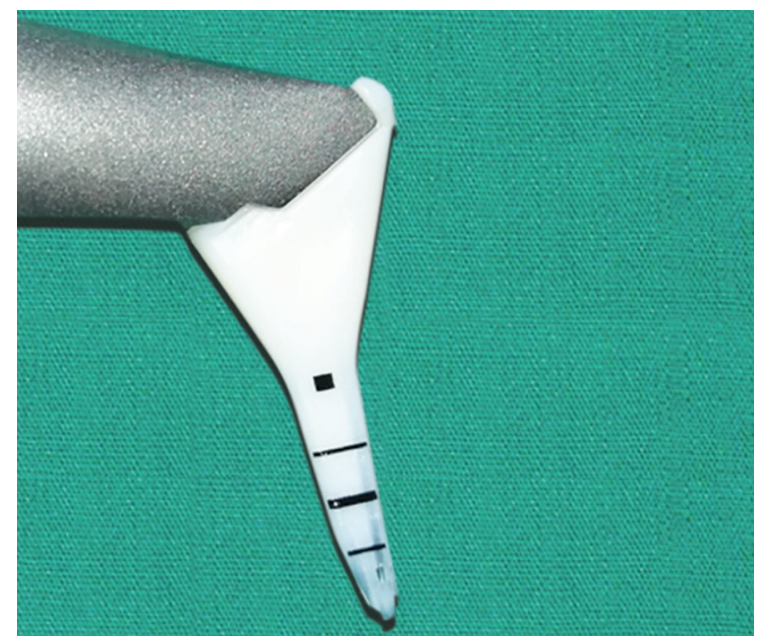

Fig. 3: Nozzle for subgingival glycine air polishing in periodontal pockets

(Table 3). GPAP group had significantly lower VAS compared to MCD group ( $p=0.038$ ) (Fig. 5).

\section{AgP Group Results}

In similar fashion, GPAP and MCD AgP groups had improvement in the mean of the periodontal indices before and after treatment with statistically significant difference $(p>0.05)$ Table 4.

At the 3 months interval, there were no statistically significant differences in mean values of periodontal clinical parameters between the two groups ( $p>0.05$ ). Table 3 VAS scores were significantly higher in the MCD as opposed to GPAP group $(p=0.018)$ (Fig. 5).

\section{ChP vs AgP}

There were no statistically significant differences in the mean values of periodontal parameters between GPAP groups and MCD groups between groups ( $p>0.05)$. However, BOP scores improved significantly in ChP group compared to $\mathrm{AgP}$ group ( $p=0.001)$ Table 3.

\section{Discussion}

The main objective of this study is to evaluate the effectiveness of subgingival glycine air polishing during PMT phase. The current study is the first study comparing the effectiveness of glycine subgingival air polishing in aggressive and chronic periodontitis patients during PMT.

Our results have been consistent with the results of several previous studies showing that subgingival air polishing with

Table 2: Mean \pm SD (standard deviation) clinical periodontal indices in ChP group at baseline and at 3 months post-therapy

\begin{tabular}{|c|c|c|c|c|c|c|}
\hline \multirow[b]{2}{*}{$\begin{array}{l}\text { Clinical } \\
\text { parameter ChP }\end{array}$} & \multicolumn{3}{|c|}{$M C D$} & \multicolumn{3}{|c|}{ GPAP } \\
\hline & $\begin{array}{l}\text { Mean } \pm S D \\
\text { baseline }\end{array}$ & $\begin{array}{l}\text { Mean } \pm S D 3 \\
\text { months }\end{array}$ & $p$ value* & $\begin{array}{l}\text { Mean } \pm S D \\
\text { baseline }\end{array}$ & $\begin{array}{l}\text { Mean } \pm S D 3 \\
\text { months }\end{array}$ & $p$ value* \\
\hline $\mathrm{PD}(\mathrm{mm})$ & $3.23 \pm 0.48$ & $2.54 \pm 0.47$ & $<0.001$ & $3.19 \pm 0.69$ & $2.72 \pm 0.63$ & $<0.001$ \\
\hline $\mathrm{CAL}(\mathrm{mm})$ & $3.39 \pm 0.51$ & $2.73 \pm 0.52$ & $<0.001$ & $3.36 \pm 0.69$ & $2.91 \pm 0.66$ & $<0.001$ \\
\hline BOP (\%) & $77.4 \pm 26.48$ & $34.75 \pm 11.65$ & 0.001 & $73.95 \pm 20.46$ & $31.45 \pm 20.36$ & $<0.001$ \\
\hline $\mathrm{PI}$ & $1.01 \pm 0.32$ & $0.61 \pm 0.28$ & $<0.001$ & $1.06 \pm 0.43$ & $0.57 \pm 0.22$ & $<0.001$ \\
\hline $\mathrm{Gl}$ & $1.15 \pm 0.38$ & $0.67 \pm 0.39$ & $<0.001$ & $1.12 \pm 0.41$ & $0.69 \pm 0.41$ & $<0.001$ \\
\hline
\end{tabular}

MCD, manual curettes debridement group; GPAP, glycine powder air polishing group; PD, probing depth; CAL, clinical attachment level; BOP, bleeding on probing; PI, plaque index; Gl, gingival inflammation; *Wilcoxon test 
glycine alone reduces the pocket depth and bleeding on probing in moderate and deep periodontal pockets and in severe periimplantitis sites. ${ }^{17-20}$

The results of the present study also concurred with the results of several other studies that revealed that the use of glycine subgingival air polishing improved the clinical parameters without statistically significant differences with manual curettes. ${ }^{6,16}$

Table 3: Multicomparison between groups in clinical parameters

\begin{tabular}{|c|c|c|c|c|}
\hline \multirow{3}{*}{$\begin{array}{l}\text { Clinical } \\
\text { parameter }\end{array}$} & \multicolumn{4}{|c|}{$p$ value ${ }^{*}$} \\
\hline & \multicolumn{2}{|c|}{$\begin{array}{c}M C D \text { vs GPAP } 3 \text { months } \\
\text { post-therapy }\end{array}$} & \multicolumn{2}{|c|}{$\begin{array}{c}\text { AgP vs ChP } 3 \text { months } \\
\text { post-therapy }\end{array}$} \\
\hline & $A g P$ & ChP & $M C D$ & GPAP \\
\hline PD & 1.000 & 0.533 & 0.401 & 0.159 \\
\hline$C A L$ & 0.233 & 0.705 & 0.829 & 0.144 \\
\hline BOP & 0.089 & 0.256 & 0.000 & 0.001 \\
\hline PI & 0.580 & 0.806 & 0.275 & 0.701 \\
\hline Gl & 0.743 & 0.892 & 0.063 & 0.077 \\
\hline VAS $^{\#}$ & 0.018 & 0.038 & 0.365 & 0.804 \\
\hline
\end{tabular}

*Mann-Whitney $U$ test

\#Parameter was taken during therapy

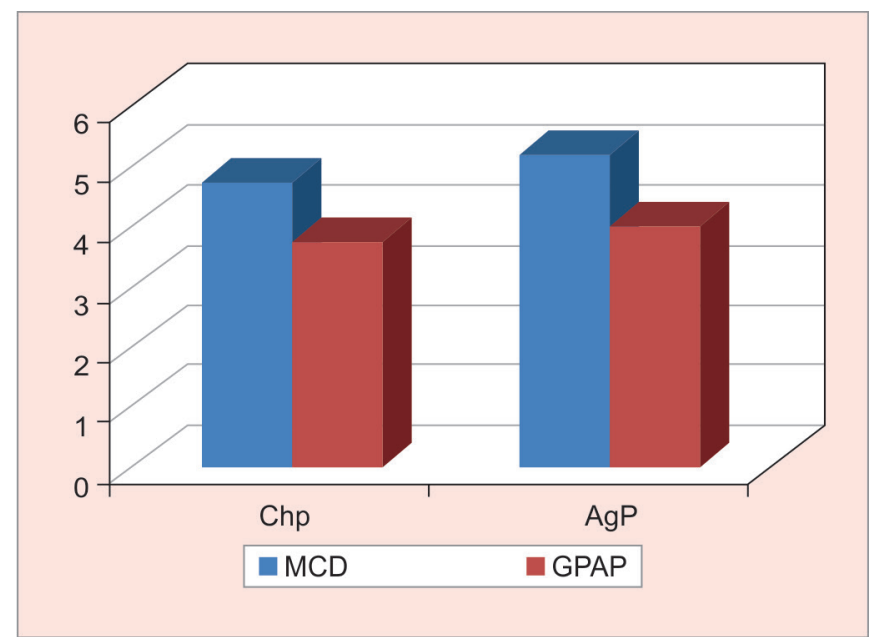

Fig. 5: Mean VAS in ChP group and AgP group during therapy. MCD, manual curettes debridement group; GPAP, glycine powder air polishing group; VAS, visual analog scale
Likewise, it is in line with data of Wennström 2011 who compared glycine subgingival air polishing with ultrasonic periodontal treatment and did not find any difference in clinical or bacterial outcomes between the two groups. ${ }^{17}$

Nonetheless, BOP in AgP group was greater than ChP group three months post-therapy; this can be due to the features of AgP which is characterized by a severe gingivitis, a large number of deepened pockets, and a high tendency for bleeding on probing. ${ }^{21}$

In terms of patient acceptance, subgingival air polishing was more comfortable for patients than manual curettes. This could be explained in the light if the properties of air polishing such as the minimal gingival irritation resulting from this treatment, as well as the size and shape of manual curettes that cause discomfort to the patient when inserted into the pocket depth. This finding is in agreement with data obtained from studies of Petersilka and Wennstrom. ${ }^{5,17}$

In order to perform air polishing in the deep pockets, many modifications were made to the conventional air polishing. A new nozzle was designed to allow access to the deep pockets, reduce air pressure by 1 bar, and make the air current with powder and water flow horizontally, instead of directing it to the pocket base. ${ }^{16}$ In addition, highly abrasive sodium bicarbonate powder has been replaced with glycine powder, a nontoxic amino acid, soluble in water, $20 \mathrm{~mm}$ in size. Thus, such changes caused less substance loss than sodium bicarbonate powder. ${ }^{7}$

The effectiveness of subgingival glycine air polishing is mainly due to the properties of the solvent produced by the air-delivered glycine powder, which is directed to the periodontal pockets by the air polishing device. ${ }^{8}$ The water stream that comes out of the nozzle itself is ineffective in removing subgingival plaque; by using water alone, there was no decrease in total bacterial counts in periodontal pockets. ${ }^{22}$ The water stream function limited the expulsion of nonadherent plaque and remaining glycine powder out of the pocket.

The current study was conducted on PMT patients because the glycine powder used in subgingival air polishing is unable to remove the calculus due to low abrasiveness and low pressure. Therefore, subgingival air polishing is considered contraindication in phase I therapy. Since the amount of calculus usually presents in the periodontal pocket after completion of initial periodontal therapy is often very small, ${ }^{23}$ subgingival air polishing with glycine powder can be used alone in PMT patients.

This improvement in the total clinical parameters in test groups also indicates that glycine subgingival air polishing is effective in removing the subgingival plaque regardless of the presence of calculus. This is confirmed by previous studies showing that there

Table 4: Mean \pm SD (standard deviation) clinical periodontal indices in AgP group at baseline and at 3 months post-therapy

\begin{tabular}{|c|c|c|c|c|c|c|}
\hline \multirow[b]{2}{*}{$\begin{array}{l}\text { Clinical parameter } \\
\mathrm{AgP}\end{array}$} & \multicolumn{3}{|c|}{$M C D$} & \multicolumn{3}{|c|}{ GPAP } \\
\hline & $\begin{array}{l}\text { Mean } \pm S D \\
\text { baseline }\end{array}$ & $\begin{array}{l}\text { Mean } \pm S D 3 \\
\text { months }\end{array}$ & $p$ value* & $\begin{array}{l}\text { Mean } \pm S D \\
\text { baseline }\end{array}$ & $\begin{array}{l}\text { Mean } \pm S D 3 \\
\text { months }\end{array}$ & $p$ value \\
\hline $\mathrm{PD}(\mathrm{mm})$ & $3.15 \pm 0.73$ & $2.42 \pm 0.6$ & $<0.001$ & $2.99 \pm 0.42$ & $2.36 \pm 0.47$ & $<0.001$ \\
\hline $\mathrm{CAL}(\mathrm{mm})$ & $3.37 \pm 0.68$ & $2.75 \pm 0.53$ & $<0.001$ & $3.18 \pm 0.45$ & $2.56 \pm 0.47$ & $<0.001$ \\
\hline BOP (\%) & $92.9 \pm 9.87$ & $69.2 \pm 21.76$ & 0.001 & $94.2 \pm 11.9$ & $54.05 \pm 21.35$ & $<0.001$ \\
\hline $\mathrm{PI}$ & $0.9 \pm 0.38$ & $0.67 \pm 0.29$ & 0.011 & $0.81 \pm 0.4$ & $0.63 \pm 0.3$ & 0.033 \\
\hline $\mathrm{Gl}^{\#}$ & $1.39 \pm 0.32$ & $0.95 \pm 0.35$ & $<0.001$ & $1.42 \pm 0.31$ & $0.96 \pm 0.38$ & $<0.001$ \\
\hline
\end{tabular}

*Wilcoxon test

"Parameter was taken during therapy 
was no significant difference in the effectiveness of plaque removal by subgingival polishing with glycine powder in treated sites with or without subgingival calculus. ${ }^{24}$

Patients were recalled after three months of treatment because several lines of evidence suggested that the interval between visits in the maintenance care phase was initially set at 3 months but may vary according to the patient's needs. ${ }^{25}$

Time saving, patient acceptance, and minimal soft tissue injury are the basic requirements for any treatment that ought to be repeated several times. This applies to all procedures used in the long-term periodontal maintenance care, especially subgingival debridement in the remaining periodontal pockets. Because the surface of the exposed root is more likely to dissolve cementum and therefore the dental sensitivity, and the subgingival plaque does not mineralize and form the subgingival calculus between the periodic visits, so the subgingival air polishing is most indicated in patients with periodontitis in the periodontal maintenance phase.

\section{CONCLUSION}

Within the limits of this study, it can be concluded that the use of subgingival glycine powder air polishing was compatible with manual curettes and yielded similar improvements in the clinical periodontal parameters after three months of treatment in patients with chronic and aggressive periodontitis during periodontal maintenance therapy. Furthermore, subgingival glycine powder air polishing was generally better perceived by the patients.

Therefore, it is suggested that subgingival glycine powder air polishing can be used as an alternative to manual curettes in patients with periodontitis during periodontal maintenance therapy.

\section{References}

1. Beikler T, Flemmig TF. Oral biofilm-associated diseases: trends and implications for quality of life, systemic health and expenditures. Periodontology 2000 2011;55(1):87-103. DOI: 10.1111/j.16000757.2010.00360.x

2. Westfelt E. Rationale of mechanical plaque control. J Clin Periodontol 1996;23(3):263-267. DOI: 10.1111/j.1600-051X.1996.tb02086.x.

3. Hujoel P, Leroux B, Selipsky H, et al. Non-surgical periodontal therapy and tooth loss. a cohort study. J Periodontol 2000;71(5):736-742. DOI: 10.1902/jop.2000.71.5.736.

4. Zappa U, Smith B, Simona C, et al. Root substance removal by scaling and root planing. J Periodontol 1991;62(12):750-754. DOI: 10.1902/ jop.1991.62.12.750.

5. Petersilka GJ, Steinmann D, Häberlein I, et al. Subgingival plaque removal in buccal and lingual sites using a novel low abrasive air-polishing powder. J Clin Periodontol 2003;30(4):328-333. DOI: 10.1034/j.1600-051X.2003.00290.x.

6. Hu C, Yin Y, Guan D. Comparison of subgingival debridement efficacy of air polishing and manual scaling. Shanghai J Stomatol 2015;24(5):602-606.

7. Pelka M, Trautmann S, Petschelt A, et al. Influence of air-polishing devices and abrasives on root dentin-An in vitro confocal laser scanning microscope study. Quintessence International 2010;41(7):e141-e148.
8. Petersilka GJ. Subgingival air-polishing in the treatment of periodontal biofilm infections. Periodontology 2000 2011;55(1): 124-142. DOI: 10.1111/j.1600-0757.2010.00342.x.

9. Petersilka GJ, Bell M, Häberlein I, et al. In vitro evaluation of novel low abrasive air polishing powders. J Clin Periodontol 2003;30(1):9-13. DOI: 10.1034/j.1600-051X.2003.300102.x.

10. Sahrmann P, Ronay V, Schmidlin PR, et al. Three-Dimensional Defect Evaluation of Air Polishing on Extracted Human Roots. J Periodontol 2014;85(8):1107-1114. DOI: 10.1902/jop.2014.130629.

11. Petersilka G, Faggion Jr CM, Stratmann U, et al. Effect of glycine powder air-polishing on the gingiva. J Clin Periodontol 2008;35(4):324-332. DOI: 10.1111/j.1600-051X.2007.01195.x.

12. Armitage GC, Svanberc GK, Löe H. Microscopic evaluation of clinical measurements of connective tissue attachment levels. J Clin Periodontol 1977;4(3):173-190. DOI: 10.1111/j.1600-051X.1977. tb02271.x.

13. Silness J, Loe H. Periodontal disease in pregnancy. II. Correlation between oral hygiene and periodontal condition. Acta Odontol Scand 1964;22:121-135. DOI: 10.3109/00016356408993968.

14. Ainamo J, Bay I. Problems and proposals for recording gingivitis and plaque. International dental journal 1975;25(4):229-235.

15. Löe H, Silness J. Periodontal disease in pregnancy I. Prevalence and severity. Acta odontologica scandinavica 1963;21(6):533-551. DOI: 10.3109/00016356309011240.

16. Moëne R, Décaillet $F$, Andersen $E$, et al. Subgingival plaque removal using a new air-polishing device. J Periodontol 2010;81(1):79-88. DOI: 10.1902/jop.2009.090394.

17. Wennström JL, Dahlén G, Ramberg P. Subgingival debridement of periodontal pockets by air polishing in comparison with ultrasonic instrumentation during maintenance therapy. J Clin Periodontol 2011;38(9):820-827. DOI: 10.1111/j.1600-051X.2011.01751.x.

18. Persson GR, Samuelsson E, Lindahl C, et al. Mechanical nonsurgical treatment of peri-implantitis: a single-blinded randomized longitudinal clinical study. II. Microbiological results.J Clin Periodontol 2010;37(6):563-573. DOI: 10.1111/j.1600-051X.2010.01561.x.

19. Renvert S, Lindahl C, Roos Jansåker AM, et al. Treatment of periimplantitis using an Er: YAG laser or an air-abrasive device: a randomized clinical trial. J Clin Periodontol 2011;38(1):65-73. DOI: 10.1111/j.1600-051X.2010.01646.x.

20. Jiang $Y$, Tong $X$. Efficacy of subgingival glycine air polishing on the treatment of moderate-mild peri-implantitis. Shanghai J Stomatol 2019;28(1):93-96.

21. Teughels W, Godts $C$, Quirynen $M$, et al. Biofilm and Periodontal Microbiology. In: Newman MG, Takei HH, Klokkevold PR, et al. ed. Carranza's Clinical Periodontology, 12th edn., Elsevier saunders; 2015. p. 165.

22. Wennström JL, Heijl L, Dahlén G, et al. Periodic subgingival antimicrobial irrigation of periodontal pockets: (I). Clinical observations. J Clin Periodontol 1987;14(9):541-550. DOI: 10.1111/j.1600-051X.1987.tb00997.x.

23. Yukna RA, Scott JB, Aichelmann-Reidy ME, et al. Clinical evaluation of the speed and effectiveness of subgingival calculus removal on single-rooted teeth with diamond-coated ultrasonic tips. J Periodontol 1997;68(5):436-442. DOI: 10.1902/jop.1997.68.5.436.

24. Flemmig TF, Hetzel $M$, Topoll $H$. Subgingival debridement efficacy of glycine powder air polishing. J Periodontol 2007;78(6):1002-1010. DOI: 10.1902/jop.2007.060420.

25. Merin RL. Supportive Periodontal Treatment. In: Newman MG, Takei HH, Klokkevold PR, et al. ed., Carranza's Clinical Periodontology: Elsevier Saunders; 2015. p. 668. 